\title{
Clinical and molecular analysis of the enamelin gene ENAM in Colombian families with autosomal dominant amelogenesis imperfecta
}

\author{
Sandra Gutiérrez ${ }^{1}$, Diana Torres ${ }^{2}$, Ignacio Briceño ${ }^{2}$, Ana Maria Gómez ${ }^{3}$ and Eliana Baquero ${ }^{3}$ \\ ${ }^{1}$ Dental Research Center, Faculty of Dentistry, Pontificia Universidad Javeriana, Bogotá, Colombia. \\ ${ }^{2}$ Human Genetic Institute, Faculty of Medicine, Pontificia Universidad Javeriana, Bogotá, Colombia. \\ ${ }^{3}$ Craniofacial Department, Faculty of Dentistry, Pontificia Universidad Javeriana, Bogotá, Colombia.
}

\begin{abstract}
In this study, we analyzed the phenotype, clinical characteristics and presence of mutations in the enamelin gene ENAM in five Colombian families with autosomal dominant amelogenesis imperfecta (ADAI). 22 individuals (15 affected and seven unaffected) belonging to five Colombian families with ADAI and eight individuals (three affected and five unaffected) belonging to three Colombian families with autosomal recessive amelogenesis imperfecta (ARAl) that served as controls for molecular alterations and inheritance patterns were studied. Clinical, radiographic and genetic evaluations were done in all individuals. Eight exons and three intron-exon boundaries were sequenced for mutation analysis. Two of the five families with ADAI had the hypoplasic phenotype, two had the hypocalcified phenotype and one had the hypomaturative phenotype. Anterior open bite and mandibular retrognathism were the most frequent skeletal abnormalities in the families with ADAI. No mutations were found. These findings suggest that ADAl in these Colombian families was unrelated to previously described mutations in the ENAM gene. These results also indicate that other regions not included in this investigation, such as the promoter region, introns and other genes should be considered as potential ADAl candidates.
\end{abstract}

Key words: amelogenesis imperfecta, ENAM gene, hypocalcified, hypoplasic, phenotype.

Received: September 11, 2011; Accepted: April 9, 2012.

\section{Introduction}

Amelogenesis imperfecta (AI) is as a group of clinically heterogeneous inherited disorders that affect the quality and quantity of enamel in infant and adult dentitions; there are no systemic manifestations associated with AI (Witkop et al., 1971). Affected individuals have greater dental sensitivity that predisposes them to caries and periodontal problems. These individuals also suffer from esthetic problems that lead to psychological difficulties and low self-esteem. Amelogenesis imperfecta has been classified in four categories based primarily on its phenotype: hypoplasic, hypomaturative, hypocalcified and hypomaturative-hypoplasic with taurodontism (Witkop, 1989); these categories are further subdivided into 14 subtypes based on phenotype and mode of inheritance. To date, six genes have been implicated in non-syndromic forms of AI: AMELX (MIM 300391), ENAM (MIM 606585), MMP20 (MIM 604629), KLK4 (MIM 603767), FAM83H (MIM 611927) and WDR72 (MIM 613214) (Stephanopoulos et al., 2005; Kim et al., 2008; El-Sayed et al., 2009). In syndromic forms

Send correspondence to Sandra Gutiérrez. Centro de Investigaciones Odontológicas, Facultad de Odontología, Pontificia Universidad Javeriana, Carrera 7 № 40-62, Bogotá, Colombia. E-mail: s.gutierrez@javeriana.edu.co. of AI, mutations in the DLX3 (MIM190320) gene cause tricho-dento-osseous syndrome, an autosomal-dominant disorder characterized by curly hair, enamel hypoplasia and taurodontism (Stephanopoulos et al., 2005; Parry et al., 2009). In addition, mutations in CNNM4 (MIM 217080) cause the Jalili syndrome characterized by the presence of cone rod dystrophy and AI (El-Sayed et al., 2009).

Autosomal dominant amelogenesis imperfecta (ADAI) is the most common form of AI in the general population and has been associated primarily with a mutation in the gene ENAM that codes for the protein enamelin (Rajpar et al., 2001). Enamelin has an important role in mineralization during which it initiates the deposition of enamel through the external surface of the distal membrane of the ameloblast. In the absence of enamelin the mineralization front fails and there is inadequate formation of enamel crystals leading to the deposition of fragile material that cannot withstand masticatory functions (Fukae et al., 1987b).

The ENAM gene is located on chromosome 4q 13.3 and has 10 exons, eight of which are coding ( $\mathrm{Hu}$ et al., 2000, 2001; $\mathrm{Hu}$ and Yamakoshi, 2003). To date, seven exonic and three intronic mutations have been reported in this gene, with most of them being associated with ADAI 
(Kida et al., 2002; Mardh et al., 2002; Hart et al., 2003a,b; Ozdemir et al., 2005; Kim et al., 2005; Gutiérrez et al., 2007; Pavlic et al., 2007; Kang et al., 2009; Chan et al., 2010) (Table 1). Some of these mutations appear to alter the regions associated with the sequence of the $32 \mathrm{kDa}$ cleavage product of the ENAM gene and studies in vitro have shown that this region is important in the interaction of enamelin with amelogenin; enamelin interacts cooperatively with amelogenin and can regulate the assembly of amelogenin (Tanabe et al., 1990). Defects in the $32 \mathrm{kDa}$ polypeptide can directly influence amelogenin-enamelin interactions and the formation of crystals that in turn affect the enamel phenotype (Tanabe et al., 1990; Uchida et al., 1991).

The hypoplastic phenotype has been reported in most of the families with ADAI, although the severity and location vary considerably, as does the occurrence of anomalies such as dental and skeletal anterior open bite, taurodontism and dental agenesis (Atasu and Eryilmaz, 1987; Pulgar et al., 2001; Rajpar et al., 2001). Understanding the genetic mutations involved in these alterations will be of great value in the management of these patients. Such knowledge should improve the prediction of problems associated with a given type of $\mathrm{AI}$ and therefore help in choosing the most appropriate treatment for each case.

The aim of this study was therefore to analyze the phenotype, clinical characteristics and presence of mutations in the ENAM gene in five Colombian families with ADAI and to examine the possible correlation between genotype and phenotype. For this, we analyzed eight exons and three intron-exon boundaries in the ENAM gene.

\section{Materials and Methods}

This project was approved by the institutional ethics committee of the Pontificia Universidad Javeriana. The investigation was done in full accordance with current ethical principles, including the World Medical Association Declaration of Helsinki (2002).

\section{Population and sample}

The population included five families with ADAI (15 affected individuals and 7 unaffected) and three families with autosomal recessive amelogenesis imperfecta (ARAI; three affected and five unaffected individuals) that served as controls for molecular alterations and inheritance patterns. All subjects were attended at the Faculty of Dentistry of the Pontificia Universidad Javeriana in Bogotá, Colombia.

\section{Clinical and radiographic analyses}

The 30 participants read, understood and signed an informed consent form before undergoing clinical and radiographic examinations. The radiographic analysis included panoramic radiographs that were used to examine the dental anomalies (dental agenesis, taurodontism, root

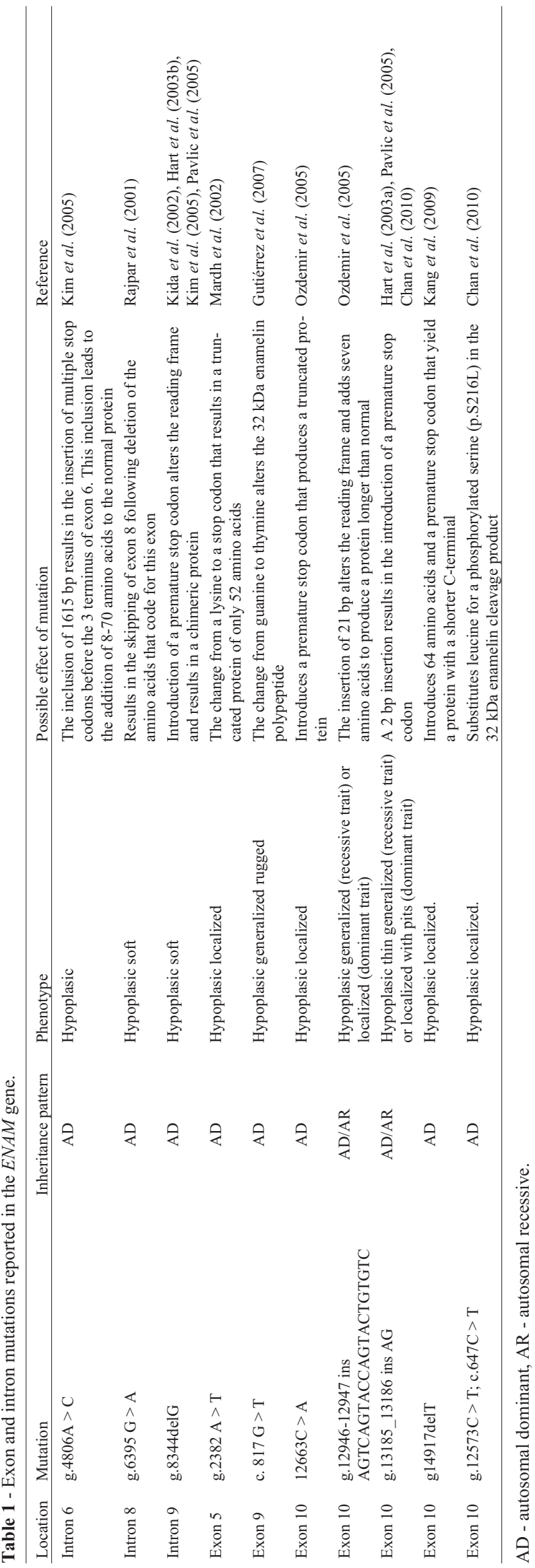


dilacerations, etc.), as previously reported (Córdoba et al., 2007), as well as x-ray profiles and skull laterals based on which cephalometric measurements were obtained to determine the craniofacial abnormalities in these patients (Table 2). Photographs were also taken to assist in the diagnosis and included images of the facial front, profile, in smile and incisor exposure at rest in affected and unaffected individuals.

\section{Phenotype and inheritance pattern}

The phenotype of AI was determined by using the classification of Witkop (1989) to determine the pattern of inheritance. Family trees were obtained using the software Cyrillic 2.1.

\section{DNA extraction and PCR amplification}

Samples of peripheral blood $(10 \mathrm{~mL})$ were obtained by venipuncture from all of the study participants. DNA was extracted by the salting out method (Miller et al., 1988). Eight exons and three intron-exon boundaries of the ENAM gene were then amplified by the polymerase chain reaction (PCR). Because of its size, exon 10 was divided into nine fragments no larger than $600 \mathrm{bp}$. The primers used to amplify the ENAM gene fragments are shown in Table 3. All of the primers were designed using PRIMER 3 software.

\section{Sequencing}

The amplified products were purified using a Wizard DNA purification system (Promega) and direct sequencing was done in both directions to establish the presence of mutations. Sequencing was done with an automatic sequencer
Table 2 - Reference values for measurements used in the cephalometric analysis of individuals with $(\mathrm{n}=18)$ and without $(\mathrm{n}=12)$ AI.

\begin{tabular}{lcc}
\hline Parameter & Reference values & Source of values \\
\hline$<$ Convexity & $12 \pm 4$ & Legan \\
Witts PO & $-1 \pm 2$ & Legan \\
SN:PM & $32 \pm 2^{\circ}$ & Steiner \\
ANB & $2.5 \pm 1.7$ & Steiner \\
PTM - N (II HP) & $52.8 \pm 4.1$ & Legan \\
Ar-PTM & $37.1 \pm 2.8$ & Legan \\
ENA-ENP (II HP) & $57.7 \pm 2.5$ & Legan \\
Co - A & $99.8 \pm 6.0$ & Mc Namara \\
Co - Gn & $125 \pm 2.0$ & Mc Namara \\
Ar - Go & $52 \pm 4.2$ & Legan \\
Go - Pog & $83.7 \pm 4.6$ & Legan \\
A I N & $1 \pm 2$ & Mc Namara \\
N I A (II HP) & $0.0 \pm 3.7$ & Legan \\
Pog - N I & $0 \pm 4$ & Mc Namara \\
N I Pog (II HP) & $-4.3 \pm 8.5$ & Legan \\
1sup: PP & $106-112^{\circ}$ & Steiner \\
1sup: NA & $22 \pm 2^{\circ}$ & Steiner \\
1sup: Na & $4 \pm 2$ & Steiner \\
1sup: SN & $103 \pm 2^{\circ}$ & Steiner \\
1inf: PM & $85 \pm 93^{\circ}$ & Steiner \\
1inf: NB & $25 \pm 2^{\circ}$ & Steiner \\
1inf: NB & $4 \pm 2^{\circ}$ & Steiner \\
1 sup A vertical & $1-2$ & Mc Namara \\
1 inf-Pog & $4-5$ & Mc Namara \\
ENA - GN & $61.3 \pm 3.8$ & Mc Namara \\
ENA - Me & $60.0 \pm 2.9$ & \\
\hline & & \\
\hline
\end{tabular}

Table 3 - Primers used for $E N A M$ gene amplification.

\begin{tabular}{llll}
\hline Region & Forward primer & Reverse primer & Size (bp) \\
\hline Exons & & & \\
3 & TGAAGCTTTGCTATTCATTTCA & TGTTTGGCCCTCTCAAGTGT & 246 \\
$4 / 5$ & TTCACAGACCAAAAATAAAAATCAA & AACTTCTCCTCTGAGACTGAACG & 292 \\
6 & TTAATGGATTCCTTTGGTTGC & AAAACATGTGGATTGGTGTCTC & 166 \\
7 & TGCCTTTTGGTTTGTTTTGG & CTCTCCGAGGCCATTTACAG & 374 \\
8 & TCTTTTCAATACCACATCACTCTGA & TGATGCACTGGTTTTGTTTCA & 245 \\
9 & CGAACGTGGTTTTCTCCTGT & GGGCGAATGGATTGTAATTT & 151 \\
$10 \mathrm{~A}$ & TGGGAAACAAAGGGCAATTA & CCCAAGCAAAGAAGTTCCAC & 556 \\
$10 \mathrm{~B}$ & CATGGGGCACAGACAGAATA & GGCATCCTTCTTGACCCTAA & 564 \\
$10 \mathrm{C}$ & AGAATTTGCCAAAGGGATT & ATCCTCCCTTGGTTTTGATG & 599 \\
$10 \mathrm{D}$ & CCTCAAATCAGCCAAAGGAA & GAGCTACCAGCACAGCAAGA & 562 \\
$10 \mathrm{E}$ & AGAGAGGCTCTTGCTGTGCT & CATGGCAAATGCAGAATGTT & 562 \\
$10 \mathrm{~F}$ & GAGAGGCAACAGCAAAGACC & GCAAAAGGAAACTAACTCAGACAA & 598 \\
$10 \mathrm{G}$ & TGTCTGAGTTAGTTTCCTTTTGC & GTCAAGAAAAATTTAGGGTACGAT & 600 \\
$10 \mathrm{H}$ & CCACTCTCCAAATCGTACCC & GGCAAGGGACATCCAGATAA & 597 \\
\hline Introns & & & 196 \\
6 & AGAGGATGGAGACAGCCTGA & TTATGACGTTTGGGTGCTGA & 187 \\
8 & GGAAATGGGCTATTCCCCTA & TGATGCACTGGTTTTGTTCA & 151 \\
9 & CGAACGTGGTTTCTCCTGT & GGGCGAATGGATTGTAATTT & \\
\hline
\end{tabular}


(Visible Genetics, version 2.0). Sequences were compared using reference sequence AY 167999 for ENAM.

\section{Results}

\section{Clinical description}

This study involved 30 individuals, of which 18 were affected by AI and 12 were unaffected (control group). All individuals were examined for skeletal and dental alterations. Dental agenesis, especially of the premolars, was one of the most common dental anomalies found in the families with ADAI. Pulp calcifications were present in several molars and premolars, as well as hypercementosis. Apical dilacerations were observed in several teeth. Taurodontism was seen in only one patient who was unaffected and belonged to the family with the hypomaturative phenotype.

With regard to the skeletal alterations, most of the affected and unaffected individuals belonging to the five Colombian families with ADAI had a hyperdivergent skeletal pattern and were classified as skeletal Class II. Most of the individuals with AI had a normal maxilla, whereas most of those in the control group had mandibular prognathism. Almost all individuals with ADAI and ARAI, as well as the control group, had a normal upper jaw size. The straight profile was the most frequent. Skeletal Class 11l, upper and lower micrognathia and an abnormal overbite were also observed, as was the presence of anterior open bite and deep bite in almost half of the affected individuals belonging to families with ADAI (Table 4).

\section{Phenotype and inheritance pattern}

The pattern of inheritance found in 5 families with AI was autosomal dominant while in three of the families was autosomal recessive. The phenotype in two of the families with the autosomal dominant pattern was of the hypoplastic type (localized in some members and generalized in others) with open interproximal spaces, teeth that varied in color from yellowish to brown, and vertical grooves and pits in the anterior teeth (Figures 1 and 2). Two other families with ADAI showed the hypocalcified phenotype while the remaining family had a hypomaturative phenotype. Figures 3-5 show the phenotype of one individual per family with the autosomal dominant pattern and their respective family trees. All of the families with ARAI had the hypomaturative phenotype (data not shown). Table 5 summarizes the dental and skeletal characteristics, the phenotypes and the genotypes of the five families with ADAI.

\section{Mutational analysis}

Mutational analysis of eight exons and three intronexon boundaries of the ENAM gene in eight families (five autosomal dominant families and three autosomal recessive families, the latter used as controls for molecular alterations and inheritance patterns) revealed no exonic or intronic mutations in any of the families.

\section{Discussion}

Various studies have examined the dental and skeletal alterations associated with AI. Dental abnormalities include altered tooth eruption, dental agenesis, impacted teeth, pulpal calcifications and taurodontism (Atasu and Eryilmaz, 1987; Seow, 1993; Pulgar et al., 2001; Rajpar et al., 2001). In a previous study, we observed that only one individual in the five Colombian families with ADAI examined had taurodontism (Cordoba et al., 2007). Pulp calcification was observed in two members of families with hypoplastic AI but not in families with other phenotypes.

Table 4 - Skeletal alterations in patients with and without AI.

\begin{tabular}{lll}
\hline & & Number of individuals showing the alteration \\
\cline { 2 - 3 } Skeletal alterations & Individuals with AI & Individuals without AI \\
\hline Hyperdivergency & 14 & 4 \\
Class II & 9 & 6 \\
Size of the upper jaw & Normal & Normal \\
Size of the lower jaw & 4 Micrognathic & 6 Micrognathic \\
Upper jaw position & 3 Prognathic, 1 Retrognathic & 6 Prognathic, 1 Retrognathic \\
Lower jaw position & 7 Retrognathic & 2 Prognathic, 3 Retrognathic \\
Profile & 12 Straight, 6 Convex & 6 Straight, 3 Convex \\
Size of the mandibular branch & 3 Diminished & 1 Augmented, 2 Diminished \\
Size of the mandibular body & 1 Augmented, 4 Diminished & 2 Diminished \\
Upper incisor inclination & 6 Vestibular version, 4 Palate version & 6 Vestibular version, 4 Palate version \\
Lower incisor inclination & 6 Vestibular version, 1 Lingual version & 7 Vestibular version, 1 Lingual version \\
Lower third & 10 Augmented, 1 Diminished & 3 Augmented, 2 Diminished \\
\hline
\end{tabular}

These skeletal alterations refer to 18 individuals with AI and 12 individuals without AI who ranged in age from 3 years old to $>18$ years old. Hyperdivergency (related to anterior open bite) and Class II were the most frequent skeletal alterations in patients with ADAI. The three patients with ARAI had a straight profile and normal sized lower and upper jaws. 
Dental agenesis associated with AI has also been reported, mainly in upper lateral incisors of hypoplastic and
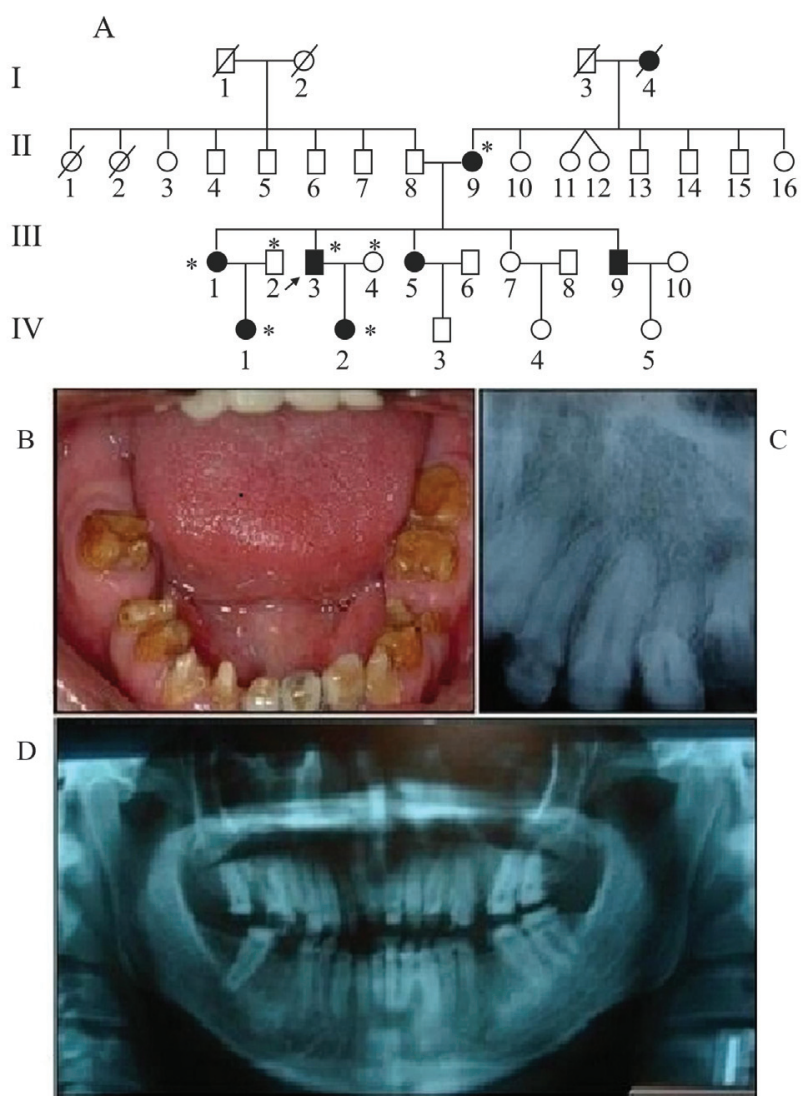

Figure 1 - Family 1. A. The pedigree indicated autosomal dominant inheritance with eight affected members (black symbols). The asterisks indicate individuals who were analyzed clinically and whose $E N A M$ gene was sequenced. Some individuals showed open anterior bite. The arrow indicates the proband III:3 patient. B. Photograph of proband III:3. The phenotype of this family was classified as generalized, rugged and severely hypoplasic with horizontal grooves. Many teeth showed caries and crown destruction while others were in the final stages of preparation for a prosthetic implant. C,D. Periapical and panorex radiographs of the same proband showing most of the teeth. Note the large areas of radiolucid enamel and the absence of several teeth. hypomaturative phenotypes (Uchida et al., 1991). We have also observed dental agenesis in five individuals with hypoplastic AI, but in premolars rather than incisors (Cordoba et al., 2007).

In addition to dental anomalies, cephalometric studies have reported that $\mathrm{AI}$ increases the prevalence of craniofacial abnormalities (Persson and Sundell, 1982; Pulgar et

A
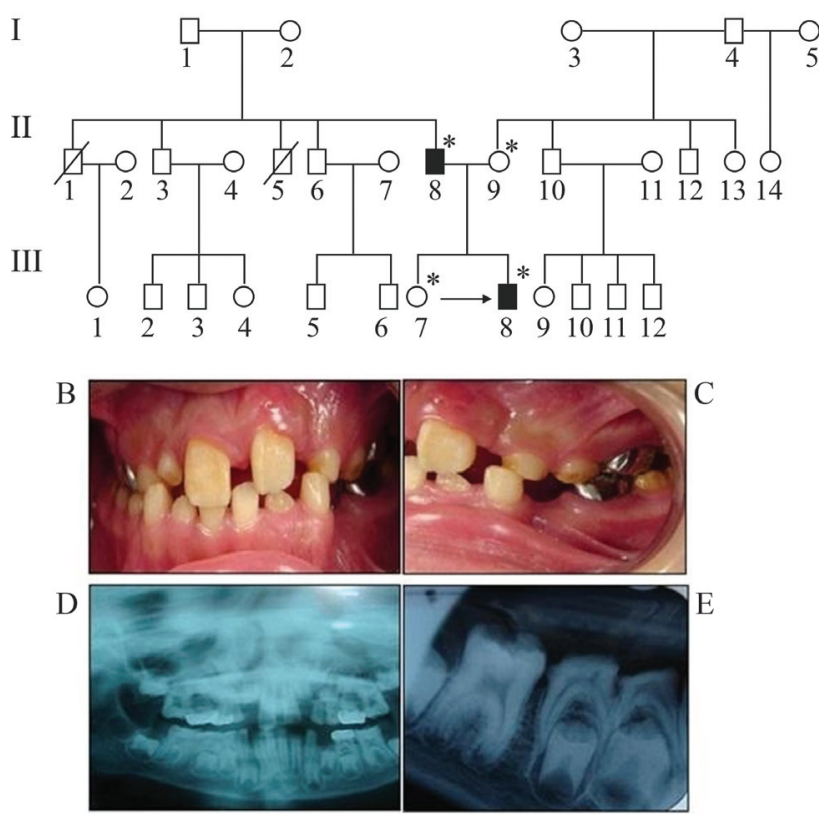

Figure 2 - Family 2. A. The pedigree indicated autosomal dominant inheritance with two affected members (black symbols). These two cases probably represent de novo mutations since none of the individuals in the first generation were affected. The arrow indicates the proband patient and the asterisks indicate individuals who were analyzed clinically and whose ENAM gene was sequenced. B, C. Photographs of proband III:8. The phenotype was classified as localized soft hypoplasic and was observed mainly in the anterior teeth. In this patient with mixed dentition, AI was present in deciduous and permanent dentition and was more severe in the latter. D,E. Panorex and periapical radiographs of the same proband showing premolars near eruption that were radiolucid in the enamel zone (similar to dentin). The periapical radiograph shows the marked contrast between dentin and enamel in the sixth permanent lower teeth.

Table 5 - Summary of the dental and skeletal anomalies, phenotypes and genotypes encountered in affected individuals belonging to the five families with ADAI.

\begin{tabular}{|c|c|c|c|}
\hline \multicolumn{2}{|l|}{ Clinical characteristics } & \multirow[b]{2}{*}{ Phenotype } & \multirow[b]{2}{*}{ Genotype } \\
\hline Dental & Skeletal & & \\
\hline $\begin{array}{l}\text { Pulpal calcifications, radicular dilacer- } \\
\text { ations, hypercementosis, dental agenesis }\end{array}$ & $\begin{array}{l}\text { Class II inferior malocclusion, inferior micrognathism, re- } \\
\text { duced mandibular size, convex profile, mandibular retro- } \\
\text { gnathism, reduced mandibular body, hyperdivergency, ante- } \\
\text { rior open bite }\end{array}$ & $\begin{array}{l}\text { Hypoplasic generalized } \\
\text { rugged }\end{array}$ & No mutations \\
\hline Pulpal calcifications, dilacerations & Normal mandibular size & $\begin{array}{l}\text { Hypoplasic soft local- } \\
\text { ized }\end{array}$ & No mutations \\
\hline $\begin{array}{l}\text { Pulpal calcifications, dilacerations, hyper- } \\
\text { cementosis, dental agenesis }\end{array}$ & Skeletal class I and class II mandibular retrognathism & $\begin{array}{l}\text { Hypomaturative gener- } \\
\text { alized snow capped }\end{array}$ & No mutations \\
\hline Hypercementosis, dilacerations & Upper prognathism, convex profile, anterior open bite & $\begin{array}{l}\text { Generalized } \\
\text { hypocalcified }\end{array}$ & No mutations \\
\hline $\begin{array}{l}\text { Pulpal calcifications, dilacerations, } \\
\text { hypercementosis, dental agenesis }\end{array}$ & Convex profile & $\begin{array}{l}\text { Generalized/localized } \\
\text { hypocalcified }\end{array}$ & No mutations \\
\hline
\end{tabular}


A
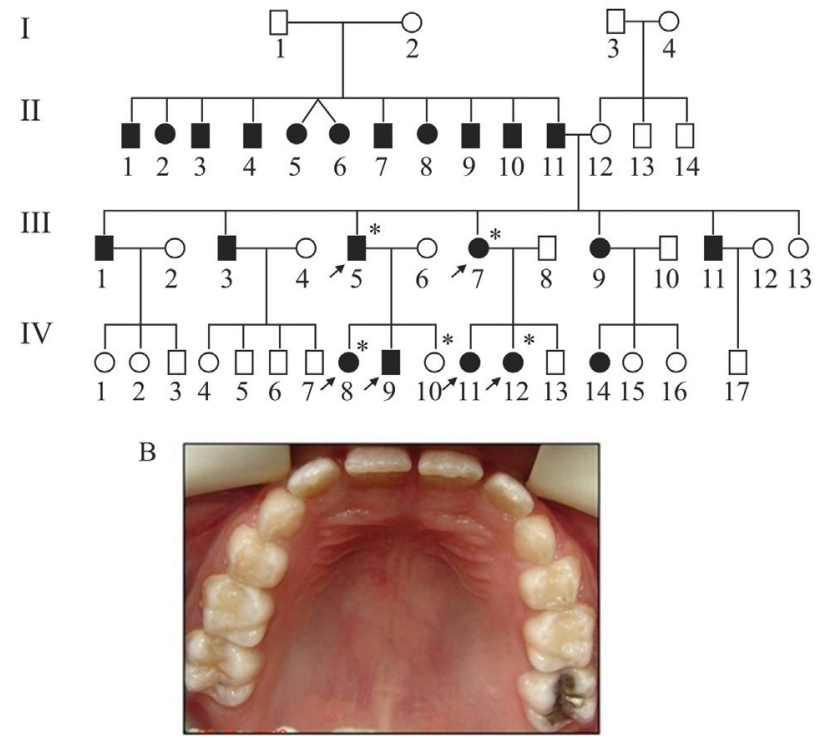

Figure 3 - Family 3. A. The pedigree indicated autosomal dominant inheritance with 22 affected members (black symbols). The arrows show the proband patients who were attended in this study and the asterisks indicate individuals who were analyzed clinically and whose ENAM gene was sequenced. B. Photograph of proband IV:8. The AI phenotype in this family was classified as hypomaturative (snow capped) with characteristics similar to fluorosis. Grooves with white stains that varied in location and intensity were observed among different members of the family. These alterations were observed mainly in the cuspids.

A

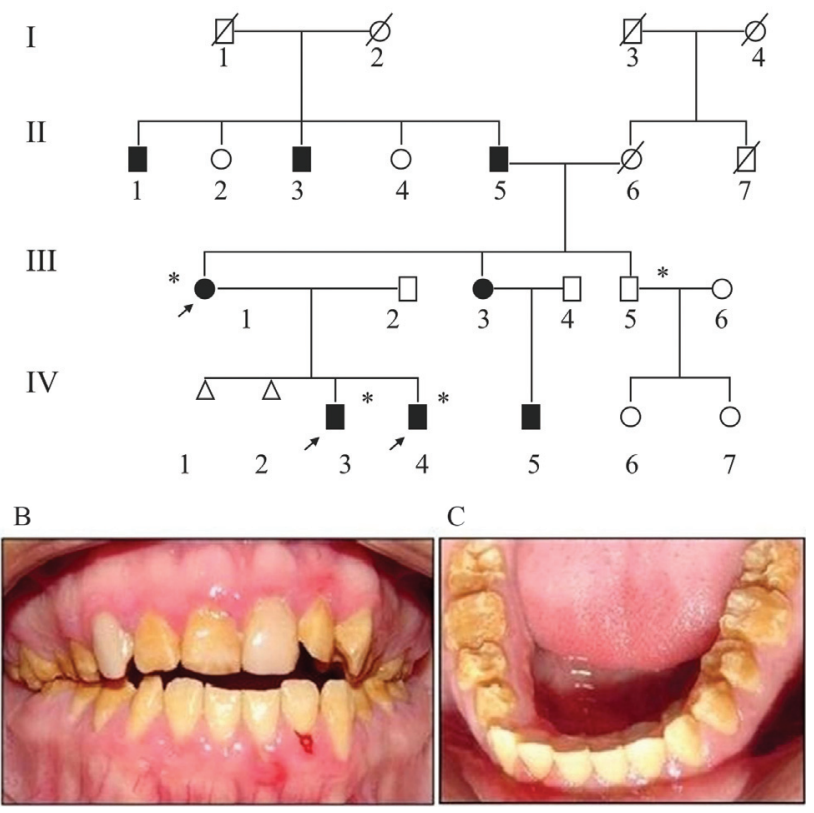

Figure 4 - Family 4. A. The pedigree indicated autosomal dominant inheritance with eight affected members (black symbols). The arrows show the proband patients who were attended along with their mother. The asterisks indicate individuals who were analyzed clinically and whose ENAM gene was sequenced. B,C Photographs of proband III:1. The phenotype was classified as generalized hypocalcified. Note the characteristic indications of wear on the occlusal surfaces and therefore high tooth sensitivity. This patient also showed anterior open bite. al., 2001). As shown here, 13 of the 18 individuals with AI had a hyperdivergent mandibular plane while seven of the 12 individuals without AI also had hyperdivergence. This retroclined mandibular plane suggests a tendency or predisposition to develop a skeletal anterior open bite. However, this condition was not unique to patients with AI since it was also observed in a significant number of individuals in the control group. Person and Sundell (1982) examined Swedish individuals with AI and found that only $38 \%$ of individuals with hypocalcified and hypoplastic phenotypes had anterior open bite and this was more common in men. Rowley et al. (1982) found skeletal anterior open bite in $24 \%$ of English subjects with the hypoplastic phenotype and a lower frequency in individuals with the hypocalcified phenotype. So far there have been no reports of anterior open bite in individuals with the hypomaturative phenotype. The results of the present study agreed with these authors, i.e., that individuals who had anterior open bite belonged to families with hypoplastic and hypocalcified phenotypes while this skeletal abnormality was not seen in subjects with the hypomaturative phenotype.

Schulze (1957) reported anterior open bite in three families with the hypoplastic phenotype of AI. The coexistence of these two conditions may reflect a pleiotropic action of genes that produce $\mathrm{AI}$ and its influence craniofacial growth (Issel, 1955; Schulze, 1957). Backman et al. (1988) stated that the frequent association of open bite with AI was possibly related to local mechanical activity such as that as-

A

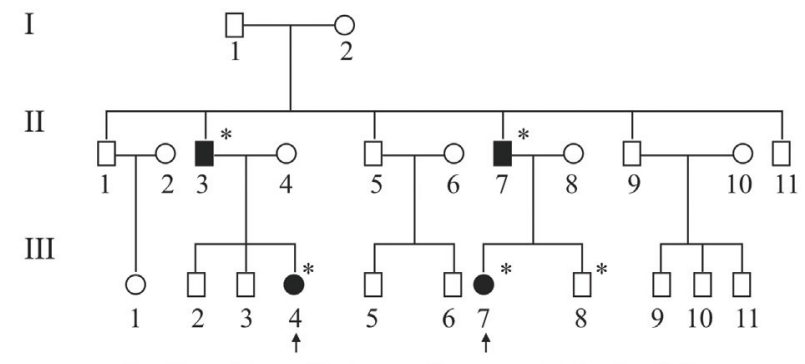

B

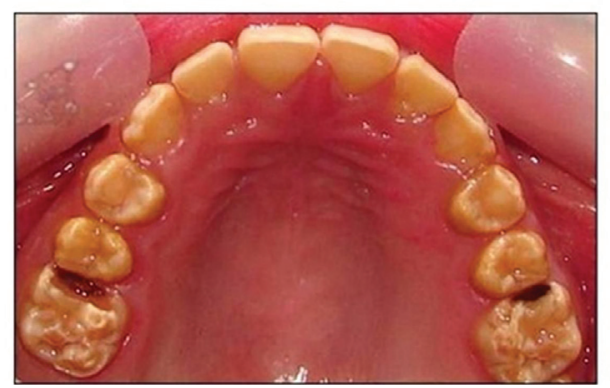

Figure 5 - Family 5. A. The pedigree indicated autosomal dominant inheritance. The arrows indicate the proband patients and the asterisks indicate individuals who were analyzed clinically and whose $E N A M$ gene was sequenced. B. Photograph of proband III:7. The AI phenotype in this family was classified as hypocalcified. However, AI was not generalized among members of this family but was restricted to hypocalcified areas. This individual showed no signs of wear on the occlusal surfaces, probably because of her young age. 
sociated with speaking since this involves changes in temperature to which the altered enamel of these individuals is sensitive. In addition, the interposition of the tongue during speaking impedes alveolar growth and leads to anterior open bite.

Several reports have indicated an association between AI caused by mutations in the ENAM gene and anterior open bite (Kida et al., 2002; Hart et al., 2003a; Gutiérrez et al., 2007; Pavlic et al., 2007). Kida et al. (2002) described two individuals heterozygous for mutations in the ENAM gene who had anterior open bite in their deciduous dentition. In contrast, other studies have reported no anterior open bite in individuals with mutations in ENAM, while some have described anterior open bite and skeletal dysplasia in individuals homozygous for ENAM gene mutations but not in heterozygotes (Hart et al., 2003b; Kim et al., 2005; Ozdemir et al., 2005). Ravassipour et al. (2000) suggested that the association between AI and anterior open bite may reflect the expression of multiple genes and possibly the contribution of environmental factors. Overall, these studies indicate that anterior open bite is not a dominant trait in individuals homozygous or heterozygous for ENAM gene mutations, but may be a trait with incomplete penetrance.

The hypoplastic phenotype is the most prevalent phenotype in autosomal dominant amelogenesis. The manifestations of this phenotype include interproximal spaces between the teeth, thin enamel that is hard to the touch, rough and irregular pits and grooves, and a color that varies from yellow to brown (Witkop and Sauk, 1971). Of the five families with ADAI studied here, two had the hypoplastic phenotype, two had the hypocalcified phenotype and one had the hypomaturative "snow capped" phenotype (Figures 1-5).

Depending on the specific mutation in the ENAM gene, the phenotype ranges from a hypoplastic rough, thin widely distributed enamel that is transmitted in a dominant or recessive form to a local enamel deposition that is confined to pits and is transmitted as a dominant trait (Kida et al., 2002). Mardh et al. (2002) stated that a dominant mutation in the ENAM gene can also cause an intermediate phenotype ("hypoplastic located") in which horizontal grooves and pits surround the enamel. In a previous study of a Colombian family in which a mutation involving the substitution of a guanine for cytosine $(\mathrm{c} .817 \mathrm{G}>\mathrm{C})$ was detected in exon 9 of the ENAM gene (Gutiérrez et al., 2007) the phenotype was hypoplastic rough and was severe and widespread in all of the teeth, with vertical grooves in the canines and horizontal grooves in the front teeth; the tooth ranged from yellow to brown. The phenotype was more severe in the proband than in some members of the same family. This finding and those of Kida et al. (2002) indicate that the dominant mutations in this gene may be responsible for the rough phenotype with grooves and pits in all affected members. In the present study the hypoplastic phenotype was observed in families 1 and 2 but there were no mutations in the ENAM gene in either of these families. Anterior open bite was seen in two affected members of family 1 and AI was more severe in permanent than in deciduous teeth in individuals with mixed dentition in this family.

The phenotype in family 2 was hypoplastic smooth localized. There was no anterior open bite in either of the affected members of this family, but the phenotype was more severe in permanent than in deciduous teeth. These findings were consistent with those of other reports (Kida et al., 2002; Mardh et al., 2002; Hart et al., 2003a,b; Kim et al., 2005; Pavlic et al., 2007) in which the phenotype varied even among members of the same families with AI that had mutations in ENAM with an autosomal dominant inheritance pattern. The phenotype in family 1 ranged from medium severity to highly severe, indicating that although the phenotype was hypoplastic for all members of this family it was more severe in some than in others. This observation suggested that there was some dose-dependency in the phenotypic manifestations and that this may have affected permanent teeth more than deciduous teeth.

To date all mutations reported for the ENAM gene cause hypoplastic enamel, although the clinical and phenotypic characteristics vary according to genotype (Table 1). The reasons for these differences are not fully known and the effects of mutations in the protein are still not very well understood. The variability in clinical appearance among individuals of the same family with the same mutation may be explained by the translation of similar sized proteins that have critical functional differences (Kim et al., 2005). These differences may reflect environmental influences, the pleiotropic action of mutations or the modification of gene effects (Hart et al., 2003a) that can contribute to the deposition of hypoplastic enamel that is thin, has a porous mineralized surface and lacks a normal prismatic structure in some areas (Wright et al., 1991; Backman, 1989). These defects in enamel quality and quantity cause discoloration, susceptibility to decay, fractures and sensitivity to temperature changes.

In most individuals of families with hypoplastic phenotype the posterior teeth in particular showed destruction of the cusps that involved decay and fractures. The teeth of all individuals with AI had a yellow to brown coloration that varied according to the severity of the phenotype (Figures 1 and 2). This finding confirmed the important protective role of enamel and the dentin-pulp complex and indicated that any alteration in the process of enamel formation could adversely affect the assembly, resistance and other its properties. Such damage reduces the resistance to decay and facilitates penetration of the tooth by bacteria and acids that cause cavities.

Our previously identified mutation in the exon 9 of the ENAM gene (c.817G > C) (Gutiérrez et al., 2007) probably resulted in altered enamelin that led to severe hypoplastic phenotype through an autosomal dominant negative 
effect. This in turn, probably caused haploinsufficiency in the gene and interfered with the proper formation of enamel, possibly by affecting crystal elongation. Pavlic et al. (2007) evaluated the $32 \mathrm{kDa}$ product of the ENAM gene (which binds with high affinity to hydroxyapatite crystals in enamel through two phosphorylated serines and three glycosylated asparagines). These authors noted that this product was affected by the mutation $g$ 13 18513186insAG, which abolished one of the serines and all three N-terminal glycosylation sites. This alteration caused premature termination of amelogenesis and aborted crystal growth, thereby contributing to the phenotypic diversity seen among members of the same family. These observations indicate that mutations in critical regions of the $E N A M$ gene can produce defective enamel.

In families with the hypoplasic phenotype, any mutation in a critical region of the $32 \mathrm{kDa}$ product could theoretically lead to the inadequate formation of enamel prisms. This could account for the phenotypic variation (absence of interproximal spaces, lack of adequate enamel formation, irregularities in enamel thickness and the presence of hypoplastic areas) among members of the families studied. Animal studies have highlighted the important role of enamelin in controlling crystal nucleation and growth and have shown that enamelin is absolutely essential for proper mineralization (Hu et al., 1997; Masuya et al., 2005; Hu et al., 2008). In this function, the $32 \mathrm{kDa}$ product, which is hydrophobic and acidic, increases the acidity of enamelin and its affinity for hydroxyapatite, thereby promoting nucleation and crystal elongation ( $\mathrm{Hu}$ et al., 1997). Immunohistochemical analysis has shown a predominance of the $32 \mathrm{kDa}$ product in the inner layer of prisms containing crystals and in areas of enamel matrix; this polypeptide is also responsible for interacting with amelogenin (Uchida et al., 1991). In our previously reported mutation (Gutiérrez et al., 2007), the change in the ENAM gene sequence in the family studied with AI occurred in the region coding for the $32 \mathrm{kDa}$ product which is involved in the interaction between enamelin (primarily through the aminoglycosidic N-terminal) and amelogenin; possibly the mutation may disrupt the interaction of these two proteins.

Family 1 of the present study had a phenotype very similar to that of the family studied by Gutiérrez et al. (2007) but did not share the same ENAM gene mutation seen in the latter family. In contrast, the absence of shared ENAM mutations in family 2 compared to the family studied by Gutiérrez et al. (2007) was not surprising since the phenotype of family 2 was much less severe and was soft instead of rough. However, the presence of an autosomal dominant hypoplastic phenotype in family 2 suggests the presence of another mutation in the ENAM gene that causes this AI phenotype. Our findings generally agree with those of Kim et al. (2006) who reported that only six of 24 families with an autosomal dominant inheritance pattern had mutations in the ENAM gene. Overall, these results confirm the genetic heterogeneity of AI and stress the need to explore other genes.

Family 3 had the hypomaturative "snow capped" phenotype that is very similar to that of individuals with fluorosis. In these patients, there was a mixture of fluorosis with other features typical of AI (Figure 3B). Small and Murray (1978) stated that in addition to fluoride, other hereditary and environmental factors have been implicated in the etiology of enamel defects. Fejerskov et al. (1990) proposed that the term 'idiopathic dental fluorosis' should be used to classify the changes associated with enamel fluorosis that show the characteristics of fluorosis but for which a significant history of the ingestion of fluoride-containing salt or water is unavailable. Some of the clinical characteristics of patients in family 3 were very similar to fluorosis while others were very typical of AI (Figure 3B). The pedigree of this family revealed a large number of individuals affected in each generation, but there was no information on the source of the water they drank (Figure 3A). Backman et al. (1989) reported that individuals with the hypomaturative "snow capped" phenotype with autosomal dominant inheritance had mottled white areas confined to the incisal edges of the anterior and posterior cusps of the teeth, particularly the molars. This conclusion is consistent with the clinical features observed in some members of this family (Figure 3B). Individuals III:13,IV:10,IV:15,IV:16 and IV:17 were of particular interest in diagnosing the phenotype of this family (Figure 3A) since these subjects showed no defects in their enamel even though they lived in the same area and consumed water from the same source as the rest of the family. Winter (1996) reported that 32 of 48 children he studied showed defects similar to those associated with fluorosis and suggested that a large proportion of these cases could be explained by as yet undescribed inherited abnormalities of enamel.

Finally, two families in this study showed a hypocalcified phenotype characterized by poorly mineralized enamel. The teeth were yellow to orange in color and worn on the occlusal surfaces (Figures 4B,C and 5B, which show the phenotype of one individual per family). These families had no mutation in the ENAM gene. These findings agree with Hart et al. (2003a), who found no mutations in five candidate genes, including the ENAM gene, in two families with ADAI and the hypocalcified phenotype.

The extensive genetic heterogeneity of AI means that further molecular studies are needed to establish the precise role played by genes in enamel formation. Such studies would also help to explain the high degree of clinical diversity, the pattern of inheritance and the genotype involved in this condition. The phenotypic and genotypic results described here for Colombian families with ADAI and for other groups and populations described in the literature, particularly in relation to the ENAM gene, suggest that there is a need to consider other candidate genes as possible causes of this disease. Recent studies have stressed the need 
to search for the gene(s) responsible for the hypocalcified phenotype in ADAI and the FAMH83 gene has been proposed as a candidate for this phenotype (Kim et al., 2008; Urzúa et al., 2012).

Although it is still unclear why certain dental and craniofacial characteristics are associated with $\mathrm{AI}$, the study of these features could facilitate the development of comprehensive protocols for managing and treating AI patients. Novel therapeutic strategies involving professionals from different disciplines would need to address issues such as the functional, aesthetic and psychological factors that produce AI. Characterization of the genes and mutations that cause AI could lead to the development of effective gene-based therapies for treating this disease.

\section{Acknowledgments}

The authors thank Dr. Jesus Calero, Ricardo Dueñas and Myriam Luz Agudelo for their support during this work and the patients who participated in this study. We also thank the Dental Research Center and the Human Genetic Institute of Javeriana University, Bogotá, Colombia, for logistic support. This work was supported financially by COLCIENCIAS and the academic vice-rectory of Javeriana University.

\section{References}

Atasu M and Eryilmaz A (1987) Congenital hypodontia of lateral incisor in association with coloboma of the iris and hypomaduration type of amelogenesis imperfecta in a large kindred. J Clin Pediatr Dent 21:341-355.

Backman B and Holmgren G (1988) Amelogenesis imperfecta: A genetic study. Hum Hered 38:189-206.

Backman B, Anneroth G and Horstedt P (1989) Amelogenesis imperfecta: A scanning electron microscopic and microradiographic study. Oral Pathol 18:140-145.

Chan HC, L Mai, A Oikonomopoulou, HL Chan, AS Richardson, SK Wang, JP Simmer and JC-C Hu (2010) Altered enamelin phosphorylation site causes amelogenesis imperfecta. J Dent Res 89:695-699.

Córdoba CA, Gutiérrez SJ and Gamboa LF (2007) Anomalías dentarias presentes en Amelogenesis imperfecta. Rev Acad Col Odontoped 5:9-14.

El-Sayed W, Parry DA, Shore RC, Ahmed M, Jafri H, Ra-shid Y, Al-Bahlani S, Al Harasi S, Kirkham J, Inglehearn CF, et al. (2009) Mutations in the beta propeller WDR72 cause autosomal-recessive hypomaturation amelogenesis imperfecta. Am J Hum Genet 85:699-705.

Fejerskov O, Manji F and Baelum V (1990) The nature and mechanisms of dental fluorosis in man. J Dent Res 69:692-700.

Fukae M and Tanabe T (1987b) Nonamelogenin components of porcine enamel in the protein fraction free from the enamel crystals. Calcif Tissue Int 40:286-293.

Gutiérrez SJ, Chaves M, Torres D and Briceño I (2007) Identification of a novel mutation in the enamelin gene in a family with autosomal-dominant amelogenesis imperfecta. Arch Oral Biol 52:503-506.
Hart TC, Hart PS, Gorry MC, Michalec MD, Ryu OH, Uygur C, Ozdemir D, Firatli S, Aren G and Firatli E (2003) Novel ENAM mutation responsible for autosomal recessive amelogenesis imperfecta and localized enamel defects. J Med Genet 40:900-906.

Hart PS, Michalec MD, Seow WK, Hart TC and Wright JT (2003) Identification of the enamelin (g.8344delG) mutation in a new kindred and presentation of a standardized ENAM nomenclature. Arch Oral Biol 48:589-596.

Hu CC, Fukae M, Uchida T, Qian Q, Zhang CH and Ryu OH (1997) Sheathlin: Cloning cDNA/polypeptide sequences and immunolocalization of porcine enamel sheath proteins. J Dent Res 76:648-657.

Hu CC, Hart TC, Dupont BR, Chen JJ, Sun X and Qian Q (2000) Cloning of human enamelin cDNA, chromosomal localization and analysis of expression during tooth formation. $\mathrm{J}$ Dent Res 79:912-919.

$\mathrm{Hu} \mathrm{CC}, \mathrm{Hu}$ Y, Smith CE, McKee MD, Wright JT, Yamakoshi Y, Papagerakis P, Hunter GK, Feng JQ, Yamakoshi F, et al. (2008) Enamel defects and ameloblast-specific expression in enamelin knockout/LACZ knocking mice. J Biol Chem 283:10858-10871.

Hu JC, Zhang CH, Yang Y, Karrman-Mardh C, Forsman-Semb K and Simmer JP (2001) Cloning and characterization of the mouse and human enamelin genes. J Dent Res 80:898-902.

$\mathrm{Hu}$ JC and Yamakoshi Y (2003) Enamelin and autosomal-dominant amelogenesis imperfecta. Crit Rev Oral Biol Med 6:387-398.

Issel P (1955) Über Aplasie des Zahnschmelzes unter besonderer Berücksichtigung der prothetischen Versorgung. Zahnärztl Rundschau 64:165.

Kang HY, Seymen F, Lee SK, Yildirim M, Bahar Tuna E and Patir A (2009) Candidate gene strategy reveals ENAM mutations. J Dent Res 88:266-269.

Kida M, Ariga T, Shirakawa T, Oguchi H and Sakiyama Y (2002) Autosomal dominant hypoplastic form of amelogenesis imperfecta caused by an enamelin gene mutation at the exonintron boundary. J Dent Res 81:738-742.

Kim JW, Seymen F, Lin BPJ, Kiziltan B, Gencay K and Simmer JP (2005) ENAM mutations in autosomal dominant amelogenesis imperfecta. J Dent Res 84:278-282.

Kim JW, Simmer JP, Lin BP, Seymen F, Bartlett JD and Hu JC (2006) Mutational analysis of candidates genes in 24 amelogenesis imperfecta families. Eur J Oral Sci 114:3-12.

Kim JW, Lee SK, Lee ZH, Park JC, Lee KE, Lee MH, Park JT, Seo BM, Hu JC and Simmer JP (2008) FAM83H mutations in families with autosomal-dominant hypocalcied amelogenesis imperfecta. Am J Hum Genet 82:489-494.

Mardh CK, Backman B, Golgren G, Hu JCC, Simmer JP and Forsman-Semb K (2002) A nonsense mutation in the enamelin gene causes local hypoplastic autosomal dominant amelogenesis imperfecta (AIH2). Hum Mol Genet 11:1069-1074.

Masuya H, Shimizu K, Sezutsu H, Sakuraba Y, Nagano J and Shimizu A (2005) Enamelin (Enam) is essential for amelogenesis: ENU-induced mouse mutants as models for different clinical subtypes of human amelogenesis imperfecta (AI). Hum Mol Genet 14:575-583.

Miller SA, Dykes DD and Polesky HF (1988) A simple salting out procedure for extracting DNA from human nucleated cell. Nucleic Acids Res 16:1215. 
Ozdemir D, Hart PS, Firatli E, Aren G, Ryu OH and Hart TC (2005) Phenotype of ENAM mutations is dosagedependent. J Dent Res 84:1036-1041.

Pavlic A, Petelin M and Battelino T (2007) Phenotype and enamel ultrastructure characteristics in patients with ENAM gene mutations g.13185-13186insAG and 8344delG. Arch Oral Biol 52:209-217.

Persson M and Sundell S (1982) Facial morphology and open bite deformity in amelogenesis imperfecta. Acta Odontol Scand 40:135-144.

Pulgar ER, Espona-Garcia I and Navajas JM (2001) Amelogenesis imperfecta: Diagnosis and resolution of a case with hypoplasia and hypocalcification of enamel, dental agenesis, and skeletal open bite. Quintessence Int 32:183-189.

Rajpar MH, Harley K, Laing C, Davies RM and Dixon MJ (2001) Mutation of the gene encoding the enamel-specific protein, enamelin, causes autosomal-dominant amelogenesis imperfecta. Hum Mol Genet 10:1673-1677.

Ravassipour DB, Hart S, Hart TC, Ritter AV, Yamauchi RM and Gibson C (2000) Unique enamel phenotype associated with amelogenin gene (AMELX) codon 41 point mutation. J Dent Res 79:1476-1481.

Rowley R, Hill FJ and Winter GB (1982) An investigation of the association between anterior open bite and amelogenesis imperfect. Am J Orthod 81:229-235.

Schulze C (1957) Erbbedingte Strukturanomalien menschlicher Zähne. Acta Genet 7:23-35.

Seow WK (1993) Taurodontism of the mandibular first permanent molar distinguishes between the tricho-dento-osseous (TDO) syndrome and amelogenesis imperfecta. Clin Genet 43:240-246.

Small BW and Murray J (1978) Enamel opacities: Prevalence, classification and aetiological considerations. J Dent 6:3342.
Stephanopoulos G, Garefalaki ME and Lyroudia K (2005) Genes and related proteins involved in amelogenesis imperfecta. $\mathrm{J}$ Dent Res 84:1117-1126.

Tanabe T, Aoba T, Moreno EC, Fukae M and Shimizu M (1990) Properties of phosphorylated 32-kDa non-amelogenin proteins isolated from porcine secretory enamel. Calcif Tissue Int 46:205-215.

Uchida T, Tanabe T, Fukae M and Shimizu M (1991) Immunocytochemical, immunochemical detection of a $32-\mathrm{kDa}$ non amelogenin and related proteins in porcine tooth germ. Arch Histol Cytol 54:527-538.

Urzúa B, Ortega-Pinto A, Adorno F, Franco E, Morales-Bozo I, Moncada G, Escobar-Pezoa N, Scholz U and Cifuentes V (2012) A multidisciplinary approach for the diagnosis of hypocalcied amelogenesis imperfecta in two Chilean families. Acta Odontol Scand 70:7-14.

Winter GB (1996) Amelogenesis imperfecta with enamel opacities and taurodontism: An alternative diagnosis for 'idiopathic dental fluorosis'. Br Dent J 181:167-172.

Witkop CJ (1989) Amelogenesis imperfecta, dentinogenesis imperfecta and dentin dysplasia revisited: Problems in classification. J Oral Pathol 17:547-553.

Witkop Jr CJ and Sauk Jr JJ (1971) Heritable defects of enamel. In: Stewart RE and Prescott GH (eds) Oral Facial Genetics. Mosby, St. Louis, pp 151-226.

Wright JT, Robinson C and Shore R (1991) Characterization of the enamel ultrastructure and mineral content in hypoplastic amelogenesis imperfecta. Oral Surg Oral Med Oral Pathol 72:594-601.

Associate Editor: Mara H. Hutz

License information: This is an open-access article distributed under the terms of the Creative Commons Attribution License, which permits unrestricted use, distribution, and reproduction in any medium, provided the original work is properly cited. 